\title{
The effects of a training program using a phantom to accustom heifers to the automatic milking system
}

\author{
M. K. von Kuhlberg, ${ }^{1} \odot$ M. Wensch-Dorendorf, ${ }^{2} \odot$ J. Gottschalk, ${ }^{1}$ T. Wagner, ${ }^{3}$ N. Herrmann, ${ }^{4}$ \\ and A. Einspanier ${ }^{1 *}$ \\ ${ }^{1}$ Institute of Physiological Chemistry, Veterinary Faculty, Leipzig University, 04103 Leipzig, Germany \\ ${ }^{2}$ Biometrics and Informatics in Agriculture Group, Institute for Agricultural and Nutritional Sciences, Martin Luther University Halle-Wittenberg, \\ 06099 Halle/Saale, Germany \\ ${ }^{3}$ Agricultural Society Ruppendorf AG, 01774 Klingenberg, Germany \\ ${ }^{4}$ MAP Meißener Agricultural Products AG, 01561 Priestewitz, Germany
}

\section{ABSTRACT}

The introduction of heifers into the automatic milking system (AMS) can be associated with considerable stress for both animals and farm employees, as completely inexperienced heifers initially do not independently enter the unknown milking robot. This study investigated whether training heifers on an AMS phantom provides the possibility of preparing heifers for the following lactation at the AMS. For this purpose, 77 Holstein-Friesian heifers were randomly assigned to one of 2 experimental groups: control $(\mathrm{CON})$ or phantom (PHAN). Four weeks before calving, the PHAN group was given free access to the phantom, which was similar to the actual milking robot, so that they could explore it and be positively conditioned by feeding concentrate in the phantom. The heifers of the CON group had no contact with the phantom or the AMS before the first milking at the AMS. The milking frequency per animal per day was recorded, and the proportion of animals that had to be fetched for milking was determined, to evaluate how the animals accepted the AMS after calving. To assess the stress level of the animals before and after introduction into the AMS, fecal cortisol concentrations and rumination times of the animals were measured. Additionally, lactation performance characteristics (milk yield, milk flow, electrical conductivity of milk, and milk composition) were recorded for 77 animals. The animals trained on the phantom showed a higher milking frequency (DIM 7: $2.70 \pm 0.14$ visits/d) than the control animals (DIM 7: $2.41 \pm 0.14$ visits/d) between the 4th and 10th day of lactation. In addition, between $\mathrm{d} 1$ and $\mathrm{d} 5$, the proportion of animals that had to be fetched for milking was lower in PHAN (DIM 1: $35.18 \pm 4.16 \%$ ) than in CON (DIM 1: $48.03 \pm 4.46 \%$ ).

Received April 15, 2020

Accepted July 13, 2020.

*Corresponding author: einspanier@vetmed.uni-leipzig.de
The PHAN heifers had unexpectedly high fecal cortisol levels (1 wk prepartum: $43.50 \pm 0.93 \mathrm{ng} / \mathrm{g}$ of feces), although not considerably elevated compared with CON (1 wk prepartum: $40.76 \pm 1.05 \mathrm{ng} / \mathrm{g}$ of feces). Training on the phantom had no appreciable influence on rumination time and lactation performance parameters. The increased number of milking visits and the reduced proportion of animals that had to be fetched into the AMS for milking indicate that training on the phantom prepares the animals well for being milked in the AMS. Therefore, training heifers on the phantom offers the possibility to facilitate the start into early lactation for the animals, providing a valuable contribution to improvement of animal welfare.

Key words: automatic milking, adaptation, heifer, cortisol

\section{INTRODUCTION}

Since their market launch in 1992, automatic milking systems (AMS) have been steadily gaining in popularity, as the AMS can provide some important advantages when properly managed. The system, which is based on independent and voluntary milking visits of cows, can not only increase the daily milk yield by increasing milking frequency (Vijayakumar et al., 2017) but also improve cow comfort by giving the cow the ability to decide individually when to be milked. In addition, some producers perceive working with the AMS as less stressful and strenuous, with increased time flexibility (Tse et al., 2018). However, these benefits depend to a large extent on the herd's acceptance of the AMS and on the fact that the animals visit the AMS regularly and independently for milking. Consequently, it is important to make milking as pleasant as possible for cows, to ensure that the animals are willing to continue their voluntary milking visits. It is common practice to offer the animals concentrated feed in the AMS to make visits more attractive. However, heifers 
that are completely inexperienced with the procedure in the AMS at the beginning of their first lactation often do not ingest the concentrate, resulting in a lack of positive conditioning (Jago and Kerrisk, 2011). On the contrary, heifers often show severe stress reactions, such as kicking and stepping as well as vocalization and elimination during their first visits in the milking robot (Jacobs and Siegford, 2012). This is compounded by the unknown environment, which can also be a severe stressor (Grandin, 1997; Rushen et al., 2001). At the beginning of their first lactation, the animals have to adapt to some changes in their environment, such as the unknown milking system. Therefore, the initial period at the AMS can be very stressful and demanding for both animals and staff, because the animals often have to be fetched for milking several times a day (Tse et al., 2018). Thus, an adequate acclimatization period is crucial to allow animals to adapt to the new circumstances (Weiss et al., 2005).

Even though training heifers before parturition is common practice in conventional milking systems (Donohue et al., 2010), and despite the fact that the AMS has become an inherent part of dairy farming for some years, limited studies have been performed on possible training methods for the AMS. Most of the training methods of these studies, as well as the recommended training protocols of the AMS manufacturers, include fetching the animals into the AMS repeatedly for several days during the training period (Donohue et al., 2010; Jago and Kerrisk, 2011), which in turn can lead to a relatively demanding period. Some producers may be discouraged from acclimating their animals to AMS before the first milking, due to the additional time and effort required for training (Tse et al., 2018). In some cases, training at the AMS is not even possible: for example, if the AMS is already operating at full capacity due to lactating animals (Donohue et al., 2010). However, studies conducted on training at the AMS have shown that habituation to the AMS have positive effects on animal welfare and productivity. According to a study by Widegren (2014), prepartum habituation to AMS has a positive effect on milking frequency and milk production. Donohue et al. (2010) also showed that training heifers resulted in a milking frequency of heifers comparable to that of their experienced herd mates. Weiss et al. (2005) observed that the proportion of fetched animals, heart rate, and daily milk yield were influenced by previous AMS experience. The aim of the current study was to investigate whether heifers can be acclimated to the AMS prepartum by training on an AMS phantom, to which they had free access to explore it voluntarily without human assistance, and whether this training affects acceptance of the AMS, the stress response, and early-lactation performance.

\section{MATERIALS AND METHODS}

\section{Animals and Housing}

This study was conducted between March and August 2017 on a Saxon dairy farm in Germany to examine the effects of a training program using a phantom (as described later) to habituate primiparous cows to the AMS. The Holstein-Friesian heifers were continuously housed indoors in cubicle barns and were fed twice a day with a TMR or with a partial mixed ration (PMR) after calving. All cows, including the experimental animals, were milked on a Lely Astronaut A4 milking robot (Lely Industries NV, Maassluis, the Netherlands) with free cow traffic. At that time animals were fed with a PMR, as AMS visits were rewarded by feeding concentrate. The amount of concentrate offered at the AMS varied according to lactation stage and expected milk yield.

In total, 77 pregnant and healthy Holstein-Friesian heifers were selected for calculated calving date and randomly divided into 2 experimental groups, a control group (CON; $\mathrm{n}=34$ ) and a phantom group (PHAN; $\mathrm{n}=43)$. The age at first calving was $23.23 \pm 1.37 \mathrm{mo}$ $($ mean \pm SD) for CON heifers and $23.23 \pm 1.51$ mo for PHAN heifers. The divergence in group size between PHAN and CON is due to logistical challenges and company internal processes.

\section{Experimental Design}

The heifers of the PHAN group were introduced to the AMS phantom 4 wk before calculated calving date in the preparatory pen, with free access to explore the phantom and positive conditioning with concentrate. The phantom is built similarly to the Lely Astronaut A4 and is installed at the edge of the barn unit, like the actual milking robot, to familiarize the heifers with their future milking situation (Figure 1). However, as the milking arm does not attach to the udder of the nonlactating animals, it has been simplified so that it only visually corresponds to the milking arm of the AMS. In addition, the technical equipment required for milking in the actual milking robot can be dispensed with. While concentrate was being offered, the simulated simplified milking arm extended under the abdomen of the heifer without touching it or manipulating the udder. In addition, the typical sound of the AMS was played through a speaker. During this period, PHAN heifers received a PMR at the feeding fence twice a day. The PMR contained $0.51 \mathrm{~kg}$ of concentrate per animal per day. In addition, each animal received $1.25 \mathrm{~kg}$ of concentrate per day in the phantom as a reward. These $1.25 \mathrm{~kg}$ of concentrate were divided into 4 portions to 


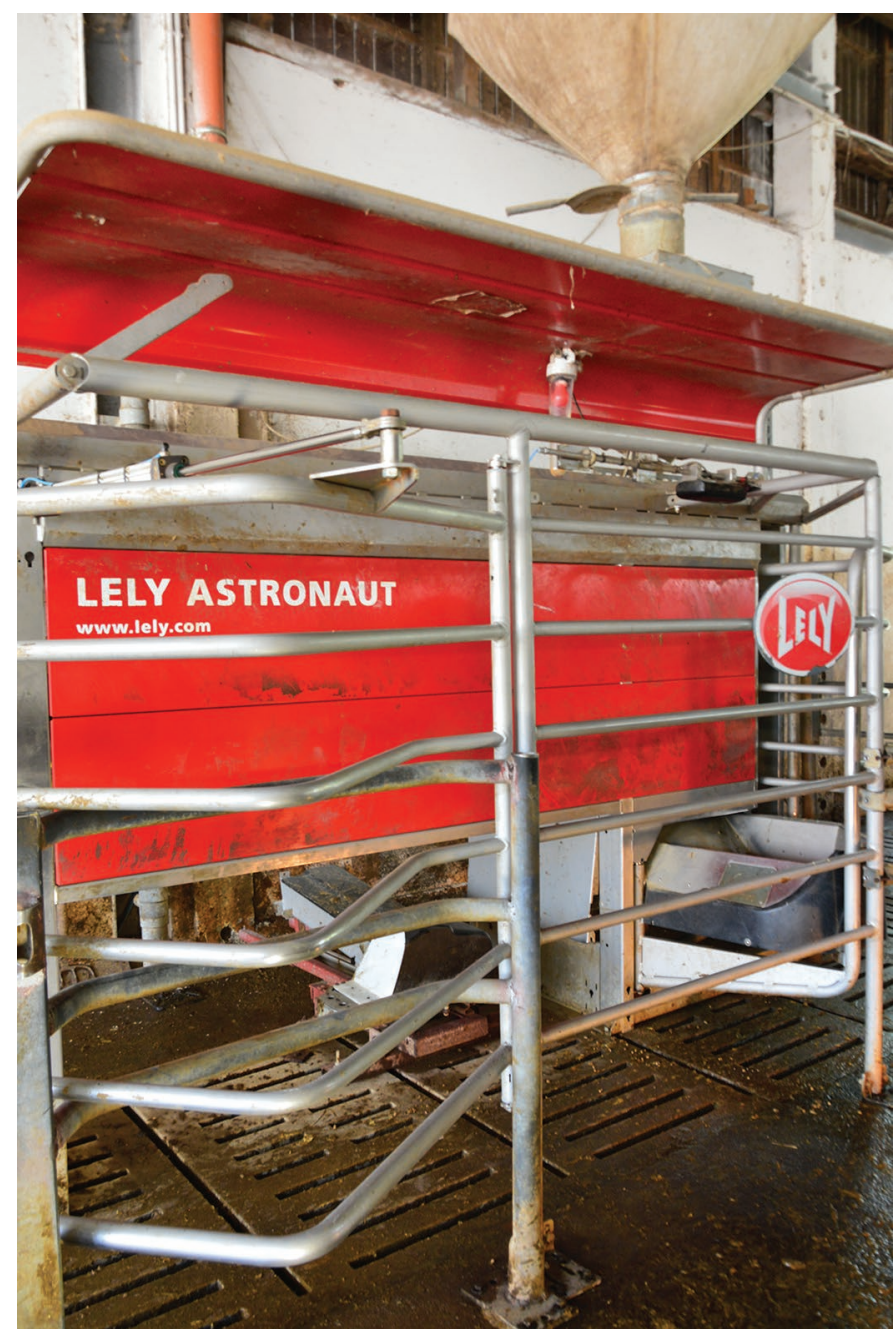

Figure 1. The phantom of a milking robot is built similarly to the Lely Astronaut A4 (Lely Industries NV, Maassluis, the Netherlands).

encourage the animals to visit the phantom 4 times a day. This was done to prepare the heifers for the procedure in the actual milking robot, where 4 milking events per day are the goal.

Heifers of the CON group were given a TMR until calving, in which the same amount of concentrate (1.76 $\mathrm{kg}$ ) was provided. The stable unit of $\mathrm{CON}$ was located in the same building as the unit of PHAN but at the opposite end of the barn. Therefore CON heifers had no visual contact with the phantom unit, and the sounds of the phantom were not audible to them. Thus their first contact with the milking robot was, as usual, at first milking in the AMS. About $7 \mathrm{~d}$ before the calculated calving date, heifers of both groups were transferred from the preparatory pen to calving pens, where they remained for a maximum of $48 \mathrm{~h}$ postpartum, without distinction between the groups. In the calving pen, co- lostrum was milked using portable milking machines. Thereafter, the animals of both experimental groups were randomly assigned to 2 milking groups, consisting of PHAN, CON, and animals in higher lactations, which were not included in this study. A milking group consisted of approximately 147 animals and had 3 milking robots at its disposal. In addition, both milking groups had the same external conditions as feed ration, management, stable construction, and number and arrangement of milking robots. For the first milking at the AMS, the animals of both experimental groups were manually driven into the AMS for supervision of the first milking and to store the teat coordinates in the milking robot for subsequent milking visits.

\section{Fecal Glucocorticoid Concentration}

To detect the effect of phantom training on fecal cortisol concentrations before, during, and after calving, fecal samples were selected from PHAN and CON every second day, from 4 wk prepartum to 6 wk postpartum. The fecal samples were collected in the morning between 0800 and $0900 \mathrm{~h}$ without fixing the animals. To ensure individual identification, fecal samples were taken directly from the rectum using a rectal glove and frozen at $-20^{\circ} \mathrm{C}$ in labeled sample containers until further analysis. Laboratory analysis of fecal glucocorticoid metabolites was performed according to the method described by Kuehnel et al. (2012). The interand intra-assay coefficients of variation were $7.8 \%$ and $6.5 \%$, respectively. The sensitivity was $4.4 \mathrm{ng} / \mathrm{g}$ of feces.

\section{Rumination Time}

Rumination time $(\mathrm{min} / \mathrm{d})$ was recorded by a data logger attached to each animal's neck with a collar (Lely Qwes-HR collars, Lely Industries NV). These data were then downloaded and stored by stationary readers in the AMS.

\section{Fetching}

Immediately after transition to the milking groups and the first assisted milking in the AMS, overdue cows (no milking in the last $12 \mathrm{~h}$ ) were fetched into the AMS every 12 h, at 0600 and 1800 h. Farm employees noted each time they had to fetch an overdue animal into the AMS. In addition, intensity of the process was evaluated with a score range from 0 to $2(0=$ no fetching necessary; $1=$ the animal had to be introduced to the AMS and needed some pressure; $2=$ the animal had to be driven into the AMS by several workers). 


\section{Data Recorded Electronically by the AMS}

The number of milking visits (defined as the number of successful milking events per cow per day), milk yield (total amount of milk per cow per day, in kilograms), average quarter milk flow (determined from the duration of milking and the milk yield, in kilograms of milk per minute), and electrical conductivity (charged separately for each quarter, specified as dimensionless value) were calculated and stored by default for each animal by the AMS. Data on milk composition were also collected, such as fat content (as percentage) and protein content (percentage) for each milking event in the AMS.

Calving performance was recorded for the experimental animals and classified into 3 categories: normal, impaired, or difficult. Normal calving performance implied that no intervention was required at parturition. In the case of impaired calving performance, obstetric assistance was required from farm employees, but the calf was delivered without any problems. Difficult calving performance required intensive obstetric or even veterinary intervention (e.g., Cesarean section). Additionally, twin calvings and stillborn calves were recorded.

\section{Statistical Analysis}

Statistical analysis was performed using the SAS 9.4 software package (SAS Institute Inc., Cary, NC). Least squares means (LSM) and standard errors were estimated using the MIXED or GLIMMIX procedure. The differences of LSM were tested for significance, and LSM were considered to be significantly different at $P$ $<0.05$. As described in Mielenz et al. (2006), we used the well-known approach suggested by Ali and Schaeffer (1987) to model test day lactation curves. The covariates defined by Ali and Schaeffer (1987) were used to model the treatment-specific regression part and the animal-specific regression part, which is called random regression test day model. For the milk yield traits and rumination time, the MIXED procedure was used, and for the count trait number of milking visits the GLIMMIX procedure in SAS, including the Poisson distribution option, was used to compare the groups within 100 $\mathrm{d}$ after calving. Fetching scores were transformed into a binary trait, scored 1 if an animal had to be fetched for milking (fetching score of 1 or 2 ) and 0 if an animal did not have to be fetched for milking. These scores were recorded for a maximum of $21 \mathrm{~d}$ after calving. The GLIMMIX procedure in SAS, with treatment as fixed effect and a treatment-specific linear regression of day, was used to compare the groups within $14 \mathrm{~d}$ after calving, and animal was used as a random effect. For the trait of cortisol, mean values for the animals were formed over weeks, with wk 0 beginning on the calving date. To compare the groups based on treatment (CON vs. PHAN) or based on calving performance (normal vs. impaired), a mixed model was used, with week, group, and their interaction as fixed effect and animal as random effect.

\section{RESULTS}

\section{Fecal Glucocorticoid Concentration}

Training on the phantom did not significantly affect $(P>0.05)$ the fecal glucocorticoid concentration of the animals over the entire experimental period. However, the fecal cortisol concentration of the PHAN group was slightly higher than that of CON. In both groups, fecal cortisol concentration declined rapidly $(P<0.01)$ at the calving event, from $1 \mathrm{wk}$ prepartum (PHAN: $43.50 \pm 0.93 \mathrm{ng} / \mathrm{g}$ of feces; CON: $40.76 \pm 1.05 \mathrm{ng} / \mathrm{g}$ of feces) to $2 \mathrm{wk}$ postpartum (PHAN: $32.11 \pm 0.96 \mathrm{ng} / \mathrm{g}$ of feces; CON: $32.21 \pm 1.10 \mathrm{ng} / \mathrm{g}$ of feces; Figure 2). Furthermore, we also observed no significant relationship between calving performance and fecal cortisol concentration $(P>0.05$; Figure 3$)$, although the group with normal calving performance showed slightly higher cortisol values over the entire observation period.

\section{Rumination Time}

Rumination time per cow per day did not differ $(P>$ $0.05)$ between the CON and PHAN groups. On average, the animals of PHAN spent $487.59 \pm 10.45 \mathrm{~min}$ and the CON $489.97 \pm 11.27$ min ruminating. Immediately

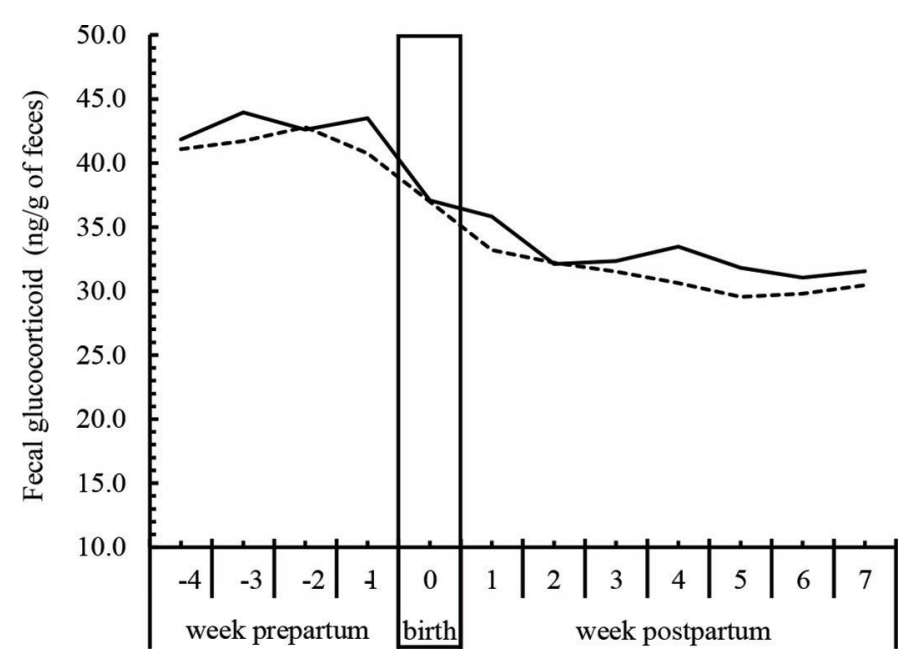

Figure 2. Weekly average values of fecal glucocorticoid concentration of the control group (dashed line) and the phantom group (solid line). 
after calving, the animals of both groups showed a low rumination time (d 1: $325.42 \pm 25.68 \mathrm{~min}$ for $\mathrm{CON}$, and $283.36 \pm 25.06$ min for PHAN), which increased steadily over the following $100 \mathrm{~d}(P<0.05)$.

\section{Fetching}

Phantom training significantly affected the proportion of animals that had to be fetched for milking between d 1 and d $5(P<0.05$; Figure 4$)$. In both groups, the proportion of animals that needed to be fetched into the AMS decreased during the first days of lactation. On d 1, after the first assisted milking, the proportion of animals that had to be fetched was $48.03 \pm 4.46 \%$ in $\mathrm{CON}$ and $35.18 \pm 4.16 \%$ in PHAN $(P=0.04)$. On $\mathrm{d}$ $5,10.94 \pm 2.33 \%$ of $\mathrm{CON}$ and $5.25 \pm 1.53 \%$ of PHAN had to be fetched for milking $(P=0.04)$. From d 6 on, we observed no significant difference between the experimental groups $(P>0.05)$. In addition, fetching that required several workers to get the animals into the AMS (score 2) were more frequent in CON (score 1: $95.60 \%$; score 2: $4.40 \%$ ) than in PHAN (score 1: 98.57\%; score 2: $1.43 \%$ ).

Number of Milking Visits. Figure 5 illustrates a significant effect of treatment $(P<0.05)$ on the number of milking visits per cow per day between $d 4$ and d 10 of lactation (e.g., d 7: $2.70 \pm 0.14$ milking visits per cow per day for PHAN vs. $2.41 \pm 0.14$ milking visits per cow per day for $\mathrm{CON} ; P=0.02$ ). In addition, we observed a tendency toward increased milking frequency for PHAN on d 3 (PHAN: $2.19 \pm 0.15$; CON: $1.95 \pm 0.15 ; P=0.06)$ and $d 11($ PHAN: $2.97 \pm 0.13$; CON: $2.75 \pm 0.13 ; P=0.06)$. Between d 80 and d 100 of lactation, PHAN likewise showed a slightly higher

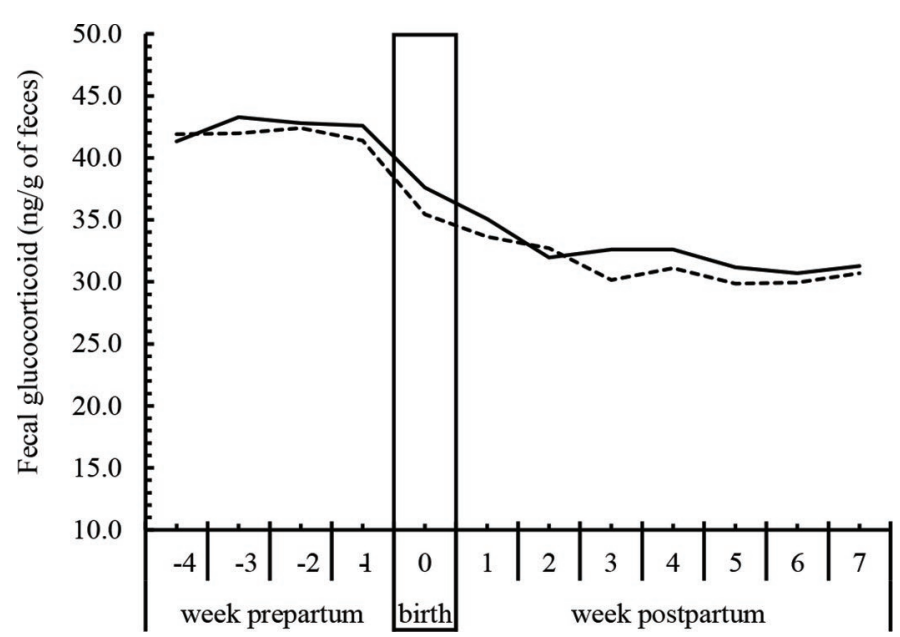

Figure 3. Weekly average values of fecal glucocorticoid concentration of the impaired calving group (dashed line) and the normal calving group (solid line).

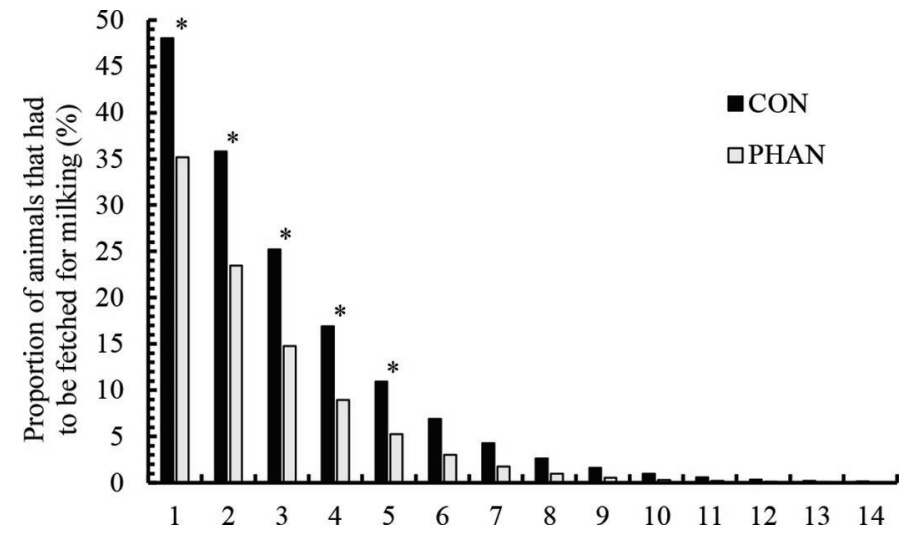

Figure 4. Proportions of animals of the control group (CON, black bars) and the phantom group (PHAN, gray bars) that had to be fetched for milking. Asterisks indicate differences $\left({ }^{*} P<0.05\right)$ between CON and PHAN on the respective day of lactation.

milking frequency. However, when averaged over the first $100 \mathrm{~d}$ of lactation, CON had $3.15 \pm 0.08$ milking visits per cow per day, and PHAN had on average 3.21 \pm 0.07 milking visits per cow per day $(P>0.05)$.

Lactation Performance and Udder Health. The average daily milk yield per cow was comparable for both experimental groups. Mean values for the first 100 DIM were $35.92 \pm 0.80 \mathrm{~kg} / \mathrm{d}$ for PHAN and 36.06 $\pm 0.87 \mathrm{~kg} / \mathrm{d}$ for CON $(P>0.05)$. Averaged over the first 100 DIM, we observed no differences $(P>0.05)$ between the groups, either in protein content (PHAN: $3.30 \pm 0.03 \%$; CON: $3.26 \pm 0.03 \%)$ or in fat content (PHAN: $3.62 \pm 0.10 \%$; CON: $3.52 \pm 0.11 \%$ ) of the milk. Both experimental groups showed a continuous increase in milk flow during the observation period of 100 DIM $(P<0.05)$. On $\mathrm{d} 5$, the milk flow was 1.88

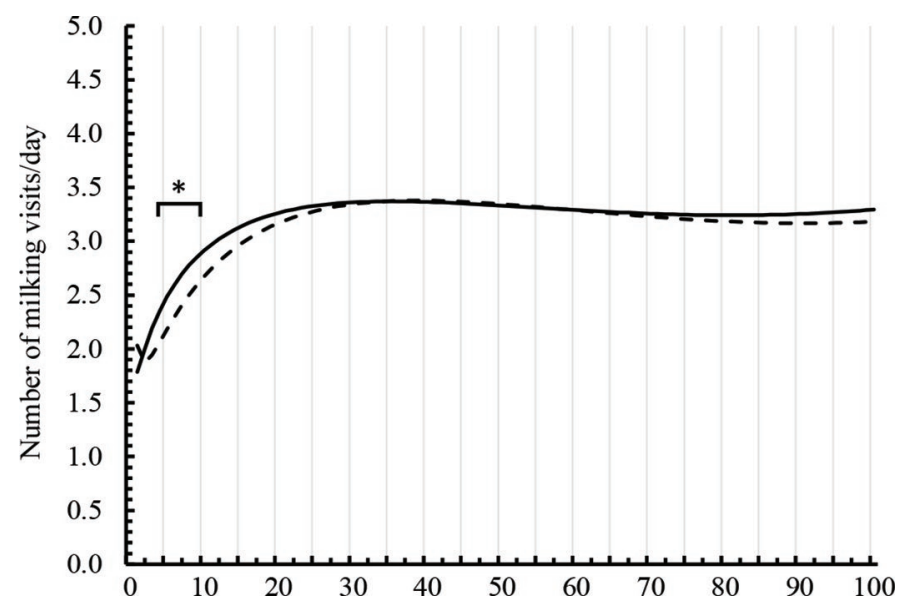

Figure 5. Average number of milking visits per day for the control group (CON, dashed line) and the phantom group (PHAN, solid line). The difference between CON and PHAN was significant from d 4 to 10 of lactation $(* P<0.05)$. 
$\pm 0.33 \mathrm{~kg} / \mathrm{min}$ for PHAN and $1.80 \pm 0.33 \mathrm{~kg} / \mathrm{min}$ for CON. The milk flow increased to $3.48 \pm 0.31 \mathrm{~kg} / \mathrm{min}$ in PHAN and $3.59 \pm 0.32 \mathrm{~kg} / \mathrm{min}$ in CON until d 100 . Averaged over the first $100 \mathrm{~d}$ of lactation, the milk flow in CON was $2.53 \pm 0.19 \mathrm{~kg} / \mathrm{min}$ and $2.51 \pm 0.17 \mathrm{~kg} /$ min in PHAN. We observed no difference between the 2 groups over the entire observation period of $100 \mathrm{~d}$ of lactation $(P>0.05)$. The electrical conductivity of milk of all 4 quarters was comparable between the 2 experimental groups. Over the entire observation period of 100 DIM, the difference between the experimental groups was not significant $(P>0.05)$.

Calving Performance. The calving process was normal for $67.6 \%$ of CON and $79.1 \%$ of PHAN. Heifers of CON had a higher percentage of impaired calving performance (32.4\%) than did heifers of PHAN (20.9\%). None of the experimental animals experienced difficult calving. At $14.3 \%$, the stillbirth rate of $\mathrm{CON}$ was markedly higher than that of PHAN (4.7\%). However, the differences in calving performance and stillbirth rates were not significant $(P>0.05)$. Only $1 \mathrm{CON}$ heifer birthed twins.

\section{DISCUSSION}

In recent years, studies have been conducted on the training of cows at the AMS, which have shown promising results and thus underlined the importance of training before introduction into the AMS (Weiss et al., 2005; Donohue et al., 2010; Jago and Kerrisk, 2011; Widegren, 2014). In the current study, we investigated the effects of a training system using a phantom to habituate prepartum heifers to AMS. The animals were able to explore the phantom independently and voluntarily, without human assistance, over a period of approximately $3 \mathrm{wk}$ in the preparatory pen. Compared with previous studies of training at the AMS, this allowed the animals a comparatively long acclimatization period; the milking robot was not obstructed by the training of nonlactating heifers; and fetching the animals during the acclimatization phase was redundant.

Because animals trained on the phantom showed a significantly higher number of milking visits between $\mathrm{d}$ 4 and d 10 of lactation, we concluded that the trained animals were familiar with the AMS and therefore entered the milking robot more frequently. The trained animals seemed to be able to transfer their acquired behavior of regularly visiting the phantom to get their concentrate feed to the actual milking robot. Widegren (2014) also found that previous training - in that case, directly at the AMS - had a positive effect on milking frequency. In addition to the number of milking visits per day, the fetching data also indicate that animals trained on the phantom accepted the AMS better than the control animals. The trained animals seemed to be in a better position to implement regular and voluntary milking visits, as, in the first $5 \mathrm{~d}$ of lactation, the proportion of animals that had to be driven into the AMS was significantly lower in PHAN than in CON. In addition, the PHAN animals needed less pressure if they had to be introduced into the AMS: at $1.43 \%$ of the fetching events, scores of 2 (several workers were needed to drive the animal into the AMS) were almost nonexistent in PHAN. This can lead to an important relief for both animals and farm employees.

Because a new environment such as the AMS can act as a severe stressor (Grandin, 1997), cortisol levels were determined, to assess the stress of the experimental animals. Our study hypothesized that animals that had previously been trained on the phantom would suffer less stress on the actual milking robot during the acclimatization period and that this would be reflected in lower fecal cortisol concentrations compared with untrained animals. The results of this study showed that in both experimental groups the fecal cortisol concentration increased before parturition, decreased sharply at the time of calving, and then remained at a low level. This well reflects the physiological process of cortisol in the periparturient period, where cortisol plays a crucial role in the initiation of parturition (Jacob et al., 2001; Vannucchi et al., 2015). However, contrary to expectations, we observed no significant increase in cortisol concentration at the time of introduction into the AMS and no significant difference between the 2 experimental groups. One explanation could be that the introduction into the AMS is only a minor stressor for the animals, which is not reflected in fecal cortisol concentrations. This was already suspected in the study by Weiss et al. (2005). However, because severe stressors, such as the transport of animals (Palme et al., 2000; Morrow et al., 2002; Möstl et al., 2002) or parturition as a physiological stressor in our study, lead to increases in fecal glucocorticoids, the method of fecal glucocorticoid determination appears to be reliable to detect severe stressors. The results of fecal cortisol concentration in the current study provided no indication that animals were exposed to stress when introduced into the AMS. At least, the stressor seems to be insufficiently strong to be reflected in the fecal cortisol concentration. However, in the current study the determination of fecal glucocorticoid metabolites does not seem to be the appropriate method to assess possible stress situations during introduction into the AMS, as, for example, it is not possible to differentiate between birth-related and stress-related cortisol secretion. Similar to our results, Weiss et al. (2005) also found unexpectedly high cortisol values in animals with previous experience with the AMS. However, these ani- 
mals received more concentrated feed due to a higher milk yield. Those authors assumed a causal relationship between the amount of concentrated feed and the fecal cortisol concentration. This might also be a reason for the slightly elevated fecal cortisol values of PHAN heifers, as they already received pure concentrated feed as a reward at the phantom before calving. However, the influence of different diets on fecal cortisol concentration is not yet confirmed. Due to their high number of milking visits and their enhanced willingness to visit the AMS voluntarily and independently, we excluded the possibility that the elevated cortisol values of PHAN cows resulted from an acquired aversion to the AMS. Because the PHAN group had a considerably higher percentage of calving performances classified as normal (79.1\%) than CON (67.6\%), and due to the fact that cortisol plays a key role in the physiological calving process, the fecal cortisol concentration was also considered with regard to the calving performance. Although the differences between the normal calving group and the impaired calving group were not significant, the group with a normal calving process showed slightly increased fecal cortisol values. It would therefore also be conceivable that the slightly elevated cortisol values of PHAN would be caused by the physiological release of cortisol during normal calving.

In addition to cortisol levels, rumination time is also suitable as an indicator of stress and cow welfare, as stressful events can lead to decrease in rumination (Malašauskienè et al., 2019). Similar to data reported by Schirmann et al. (2013) and Pahl et al. (2014), the animals of our study showed a low rumination time on the day of calving, with a significant increase postpartum. In the period after calving, the cows were exposed to some unknown situations. Factors related to the regrouping of the animals have been proven to have significant effects on rumination time and DMI (Schirmann et al., 2011). In addition, the animals of our trial were milked after calving for the first time on a milking robot. However, the cows trained on the phantom, who should have been familiar with the milking situation, did not show a significantly higher rumination time. It is conceivable that the effects of calving and then regrouping may have attenuated the effect of the phantom, or that the effect of the phantom was not sufficient to be reflected in increased rumination time.

Not only can stress experienced during or before milking affect animal welfare, the lactation performance of heifers can be adversely affected. Stress caused by milking in unknown surroundings is of particular importance, as it can lead to a central inhibition of the oxytocin release and thus to disturbed milk ejection (Bruckmaier et al., 1993; Rushen et al., 2001). This can have a negative effect on the milk flow rate and milk yield. In addition, residual milk in the udder increases the risk of mastitis, as it is an ideal medium for microorganisms in the mammary gland (Bruckmaier and Blum, 1998; Bruckmaier and Wellnitz, 2008). Because the average milk flow of the experimental animals in this study is comparable to previously published values (Hogeveen et al., 2001) and no significant differences between the experimental groups were observed, it can be concluded that neither group was influenced in milk ejection. However, the milking interval can significantly influence the milk flow rate, which was not considered in our investigation (Hogeveen et al., 2001).

Several studies have shown that increased milking frequency can lead to an increase in daily milk yield (Donohue et al., 2010; Vijayakumar et al., 2017). Weiss et al. (2005) and Widegren (2014) determined higher milking frequency and increased milk yield in cows with previous AMS experience. However, the analysis of daily milk yield in our study did not reveal any significant difference between trained and untrained animals. We suspect that the increase in milking frequency of PHAN did not differ sufficiently from that of CON, or that the period of higher milking frequency was not long enough to lead to a significantly higher daily milk yield. The results of daily milk yield also did not indicate disturbed milk ejection in either group.

Because increased milking frequency can also affect milk composition due to the potential of increased milk yield (Løvendahl and Chagunda, 2011), these values were also considered in our study. We observed no differences between the 2 experimental groups, either in protein or in fat content of the milk. The protein contents of $3.30 \%$ and $3.26 \%$ and fat contents of $3.62 \%$ and $3.52 \%$ respectively correspond with the published data (Lyons et al., 2013; Brzozowski et al., 2018).

To assess the effects of phantom training on udder health, we considered electrical conductivity during the experimental period and mastitis prevalence in firstlactation cows in the $2 \mathrm{yr}$ before installation of the phantom and the subsequent 2 yr. As already known, in mammary infections the permeability between milk and blood is altered, leading to an elevation of the ion concentration in the milk, which results in increased electrical conductivity (Linzell and Peaker, 1975). Because the sensitivity of the electrical conductivity is often unsatisfactory (Bruckmaier et al., 2004) and, additionally, in this study, electrical conductivity is given only as a dimensionless value by the AMS, this parameter should serve only as a rough estimate of udder health in our study. In all 4 quarters, milk conductivity of PHAN cows tended to be slightly lower than that of CON, but the difference was not significant. This could indicate a positive effect of the phantom on udder health, but it should not be considered a sole 
parameter, as already explained. In addition to electrical conductivity, however, the quarter infection prevalence in first-lactation cows 2 yr after the installation $(19.9 \%)$ of the phantom also showed a positive trend compared with the previous 2 yr $(21.9 \%$; T. Wagner, Agricultural Society Ruppendorf AG, Klingenberg, Germany, personal communication). As De Vliegher et al. (2012) reported that the mammary quarter infection prevalence in heifers postpartum ranges from $12 \%$ to over $57 \%$, the prevalence in the dairy farm where this study was conducted is in an acceptable range, both before the installation of the phantom and afterward.

Overall, training on the phantom provided the animals with the necessary amount of experience to perform well with the actual milking robot and to achieve a higher number of voluntary milking visits. Therefore, training on an AMS phantom is a good alternative to a training program directly at the AMS, with some important advantages, and can be an important contribution to improving animal welfare in dairy farming.

\section{ACKNOWLEDGMENTS}

The authors gratefully acknowledge the laboratory assistance of S. Tätzner (Institute of Physiological Chemistry, Faculty of Veterinary Medicine, Leipzig University, Leipzig, Germany) and G. Köller (Department for Ruminants and Swine, Faculty of Veterinary Medicine, Leipzig University). We also thank Landwirtschaftliche Rentenbank (Bonn, Germany) for supporting (grant no. 742634) and enabling this research project. We further thank Lely Industries NV (Maassluis, the Netherlands) for supporting this project. The data from the present research are applied in the $\mathrm{PhD}$ thesis of M. von Kuhlberg. The authors have not stated any conflicts of interest.

\section{REFERENCES}

Ali, T. E., and L. R. Schaeffer. 1987. Accounting for covariances among test day milk yields in dairy cows. Can. J. Anim. Sci. 67:637-644. https://doi.org/10.4141/cjas87-067.

Bruckmaier, R. M., and J. W. Blum. 1998. Oxytocin release and milk removal in ruminants. J. Dairy Sci. 81:939-949. https://doi.org/10 .3168/jds.S0022-0302(98)75654-1.

Bruckmaier, R. M., D. Schams, and J. W. Blum. 1993. Milk removal in familiar and unfamiliar surroundings: Concentrations of oxytocin, prolactin, cortisol and $\beta$-endorphin. J. Dairy Res. 60:449-456. https://doi.org/10.1017/S0022029900027813.

Bruckmaier, R. M., D. Weiss, M. Wiedemann, S. Schmitz, and G. Wendl. 2004. Changes of physicochemical indicators during mastitis and the effects of milk ejection on their sensitivity. J. Dairy Res. 71:316-321. https://doi.org/10.1017/S0022029904000366.

Bruckmaier, R. M., and O. Wellnitz. 2008. Induction of milk ejection and milk removal in different production systems. J. Anim. Sci. 86(Suppl.):15-20. https://doi.org/10.2527/jas.2007-0335.

Brzozowski, M., D. Piwczyński, B. Sitkowska, and M. Kolenda. 2018. The impact of installation of automatic milking system on produc- tion and reproduction traits of dairy cows. Reprod. Domest. Anim. 53:1123-1129. https://doi.org/10.1111/rda.13214.

De Vliegher, S., L. K. Fox, S. Piepers, S. McDougall, and H. W. Barkema. 2012. Invited review: Mastitis in dairy heifers: Nature of the disease, potential impact, prevention, and control. J. Dairy Sci. 95:1025-1040. https://doi.org/10.3168/jds.2010-4074.

Donohue, R. H., K. L. Kerrisk, S. C. Garcia, D. A. Dickeson, and P. C. Thomson. 2010. Evaluation of two training programs aimed to improve early lactation performance of heifers in a pasture-based automated milking system. Anim. Prod. Sci. 50:939-945. https:// doi.org/10.1071/AN10061.

Grandin, T. 1997. Assessment of stress during handling and transport. J. Anim. Sci. 75:249-257. https://doi.org/10.2527/1997.751249x.

Hogeveen, H., W. Ouweltjes, C. J. A. M. de Koning, and K. Stelwagen. 2001. Milking interval, milk production and milk flow-rate in an automatic milking system. Livest. Prod. Sci. 72:157-167. https:// doi.org/10.1016/S0301-6226(01)00276-7.

Jacob, S. K., V. Ramnath, P. T. Philomina, K. V. Raghunandhanan, and A. Kannan. 2001. Assessment of physiological stress in periparturient cows and neonatal calves. Indian J. Physiol. Pharmacol. $45: 233-238$.

Jacobs, J. A., and J. M. Siegford. 2012. Lactating dairy cows adapt quickly to being milked by an automatic milking system. J. Dairy Sci. 95:1575-1584. https://doi.org/10.3168/jds.2011-4710.

Jago, J., and K. Kerrisk. 2011. Training methods for introducing cows to a pasture-based automatic milking system. Appl. Anim. Behav. Sci. 131:79-85. https://doi.org/10.1016/j.applanim.2011.02.002.

Kuehnel, F., J. Grohmann, U. Buchwald, G. Koeller, D. Teupser, and A. Einspanier. 2012. Parameters of haematology, clinical chemistry and lipid metabolism in the common marmoset and alterations under stress conditions. J. Med. Primatol. 41:241-250. https://doi .org/10.1111/j.1600-0684.2012.00550.x.

Linzell, J. L., and M. Peaker. 1975. Efficacy of the measurement of the electrical conductivity of milk for the detection of subclinical mastitis in cows: Detection of infected cows at a single visit. Br. Vet. J. 131:447-461. https://doi.org/10.1016/S0007-1935(17)35240-5.

Løvendahl, P., and M. G. G. Chagunda. 2011. Covariance among milking frequency, milk yield, and milk composition from automatically milked cows. J. Dairy Sci. 94:5381-5392. https://doi.org/10 $.3168 /$ jds.2010-3589.

Lyons, N. A., K. L. Kerrisk, and S. C. Garcia. 2013. Comparison of 2 systems of pasture allocation on milking intervals and total daily milk yield of dairy cows in a pasture-based automatic milking system. J. Dairy Sci. 96:4494-4504. https://doi.org/10.3168/ jds.2013-6716.

Malašauskiené, D., M. Televičius, V. Juozaitienè, and R. Antanaitis. 2019. Rumination time as an indicator of stress in the first thirty days after calving. Pol. J. Vet. Sci. 22:363-368. https://doi.org/10 .24425 /pjvs.2019.129229.

Mielenz, N., J. Spilke, H. Krejcova, and L. Schüler. 2006. Statistical analysis of test-day milk yields using random regression models for the comparison of feeding groups during the lactation period. Arch. Anim. Nutr. 60:341-357. https://doi.org/10.1080/ 17450390600884435.

Morrow, C. J., E. S. Kolver, G. A. Verkerk, and L. R. Matthews. 2002. Fecal glucocorticoid metabolites as a measure of adrenal activity in dairy cattle. Gen. Comp. Endocrinol. 126:229-241. https://doi .org/10.1006/gcen.2002.7797.

Möstl, E., J. L. Maggs, G. Schrötter, U. Besenfelder, and R. Palme. 2002. Measurement of cortisol metabolites in faeces of ruminants. Vet. Res. Commun. 26:127-139. https://doi.org/10.1023/A 1014095618125.

Pahl, C., E. Hartung, A. Grothmann, K. Mahlkow-Nerge, and A. Haeussermann. 2014. Rumination activity of dairy cows in the 24 hours before and after calving. J. Dairy Sci. 97:6935-6941. https:/ /doi.org/10.3168/jds.2014-8194.

Palme, R., C. Robia, W. Baumgartner, and E. Möstl. 2000. Transport stress in cattle as reflected by an increase in faecal cortisol metabolite concentrations. Vet. Rec. 146:108-109. https://doi.org/10 $.1136 /$ vr.146.4.108 
Rushen, J., L. Munksgaard, P. G. Marnet, and A. M. DePassillé. 2001. Human contact and the effects of acute stress on cows at milking. Appl. Anim. Behav. Sci. 73:1-14. https://doi.org/10.1016/S0168 -1591(01)00105-8.

Schirmann, K., N. Chapinal, D. M. Weary, W. Heuwieser, and M. A. G. von Keyserlingk. 2011. Short-term effects of regrouping on behavior of prepartum dairy cows. J. Dairy Sci. 94:2312-2319. https: //doi.org/10.3168/jds.2010-3639.

Schirmann, K., N. Chapinal, D. M. Weary, L. Vickers, and M. A G. von Keyserlingk. 2013. Short communication: Rumination and feeding behavior before and after calving in dairy cows. J. Dairy Sci. 96:7088-7092. https://doi.org/10.3168/jds.2013-7023.

Tse, C., H. W. Barkema, T. J. DeVries, J. Rushen, E. Vasseur, and E. A. Pajor. 2018. Producer experience with transitioning to automatic milking: Cow training, challenges, and effect on quality of life. J. Dairy Sci. 101:9599-9607. https://doi.org/10.3168/jds .2018-14662.

Vannucchi, C. I., J. A. Rodrigues, L. C. G. Silva, C. F. Lúcio, G. A. L. Veiga, P. V. Furtado, C. A. Oliveira, and M. Nichi. 2015. Association between birth conditions and glucose and cortisol profiles of periparturient dairy cows and neonatal calves. Vet. Rec. 176:358. https://doi.org/10.1136/vr.102862.
Vijayakumar, M., J. H. Park, K. S. Ki, D. H. Lim, S. B. Kim, S. M. Park, H. Y. Jeong, B. Y. Park, and T. I. Kim. 2017. The effect of lactation number, stage, length, and milking frequency on milk yield in Korean Holstein dairy cows using automatic milking system. Asian-Australas. J. Anim. Sci. 30:1093-1098. https://doi .org/10.5713/ajas.16.0882.

Weiss, D., E. Moestl, and R. M. Bruckmaier. 2005. Physiological and behavioural effects of changeover from conventional to automatic milking in dairy cows with and without previous experience. Vet. Med. Czech. 50:253-261. https://doi.org/10.17221/5621 -VETMED.

Widegren, S. 2014. Introduction of heifers to an automatic milking system. BS thesis, Department of Animal Nutrition and Management, Swedish Univ. of Agricultural Sciences, Uppsala, Sweden.

\section{ORCIDS}

M. K. von Kuhlberg (ํ) https://orcid.org/0000-0001-5331-8336

M. Wensch-Dorendorf $\odot$ https://orcid.org/0000-0003-1634-0918 